\title{
Budd-Chiari syndrome and post-traumatic diaphragmatic hernia
}

\author{
Jussuf T. Kaifi, MD, PhD, Srinivas Kavuturu, MD, Dejah Judelson, BS, and \\ Kevin F. Staveley-O'Carroll, MD, PhD, Hershey, Pa
}

\begin{abstract}
Diaphragmatic hernias occur in as many as $6 \%$ of patients after thoracoabdominal trauma, with the majority occurring on the left side as a result of the cushioning effects of the liver. ${ }^{1}$ Diagnosis is delayed in as many as $60 \%$ of all cases, and symptoms are nonspecific and include abdominal pain, shortness of breath, chest pain, cough, and tachypnea. ${ }^{2} \mathrm{We}$ report a patient with chronic hepatothorax resulting from a right-sided diaphragmatic rupture after a remote history of blunt trauma more than 20 years previously presenting with irreversible Budd-Chiari syndrome in the right liver.
\end{abstract}

\section{CLINICAL SUMMARY}

A 24-year-old woman with an uneventful medical history came to her family physician with reports of chronic right upper quadrant pain. She underwent a chest radiograph and a computed tomographic scan, which revealed a right-sided diaphragmatic hernia with a nodular right hepatic lobe and colon herniated into the right side of the chest (Figure 1). On further questioning, the patient's mother retrospectively described a blunt thoracoabdominal trauma when the patient, as a 2-year-old child, had fallen down a flight of stairs, with subsequent significant bruising on the chest and abdomen. The family did not seek any medical consultation after that trauma. A contrast-enhanced magnetic resonance image of the liver confirmed a thrombosed right hepatic vein, with features similar to Budd-Chiari syndrome, and a hypervascular lesion $(1.1 \mathrm{~cm})$ with an early arterial phase enhancement, which was worrisome for a hepatoma in the right lobe. The left lobe of the liver was significantly hypertrophied. Liver function tests and $\alpha$-fetoprotein serum level were within normal limits. The surgical indication for diaphragmatic repair was a risk of bowel strangulation as a result of a herniated colon, and the indication for hepatectomy was a hypervascular lesion in the herniated nodular, possibly cirrhotic liver and a thrombosed right hepatic vein. A right-sided thoracoabdominal incision was performed in the 8th intercostal space

\footnotetext{
From the Department of Surgery, Penn State Milton S. Hershey Medical Center, Penn State College of Medicine, Hershey, Pa.

Disclosures: Authors have nothing to disclose with regard to commercial support. Received for publication July 14, 2011; revisions received Dec 31, 2011; accepted for publication Jan 16, 2012; available ahead of print Feb 17, 2012.

Address for reprints: Jussuf T. Kaifi, MD, PhD, FACS, Penn State Hershey Cancer Institute, Department of Surgery, Program for Liver, Pancreas and Foregut (Lung and Esophageal) Tumors, Division of Surgical Oncology, Penn State College of Medicine, 500 University Dr, H070, Hershey, PA 17033 (E-mail: jkaifi@ hmc.psu.edu). J Thorac Cardiovasc Surg 2012;143:e21-2

$0022-5223 / \$ 36.00$

Copyright (c) 2012 by The American Association for Thoracic Surgery doi:10.1016/j.jtcvs.2012.01.041
}

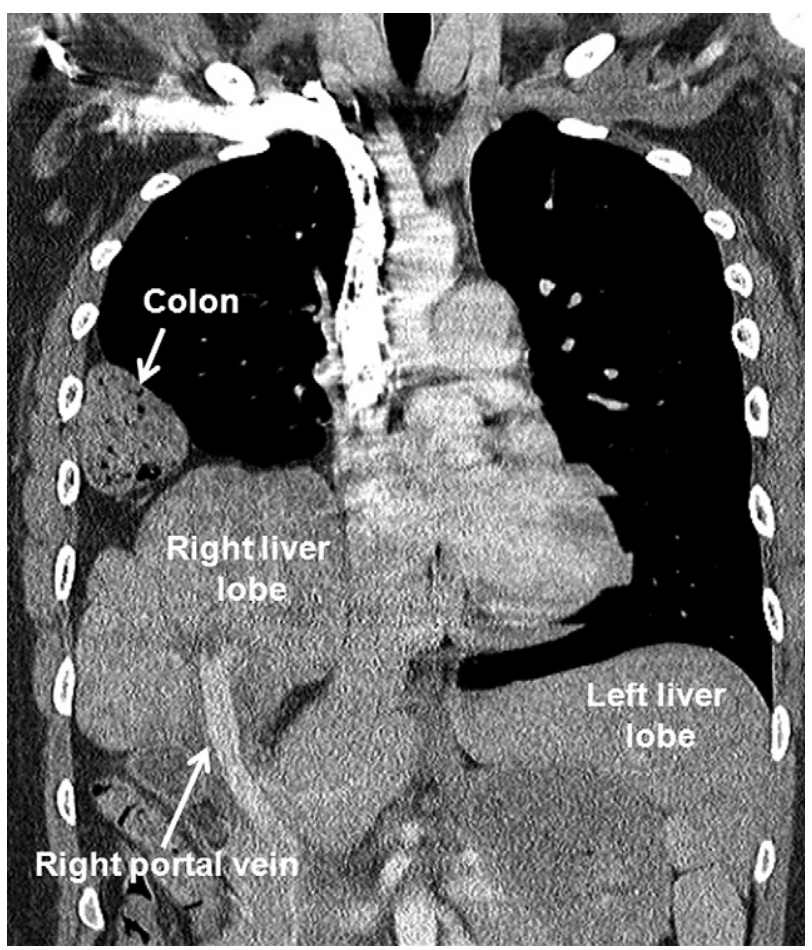

FIGURE 1. Computed tomographic scan demonstrating herniation of the nodular right liver and transverse colon into the right thorax. The left liver is hypertrophied, indicating malfunction of the right lobe.

(Figure 2). The diaphragmatic defect was located anteriorly and was $5 \times 5 \mathrm{~cm}$ in size. The nodular right lobe of the liver was completely herniated into the chest, along with part of the transverse colon. A right hepatectomy was performed, and the diaphragmatic defect was closed by primary suture repair. The patient was discharged on day 6 after an uneventful postoperative course. The pathologic analysis revealed marked venous congestion-consistent with a chronic Budd-Chiari-like syndrome-and focal scarring in the liver with no cirrhosis or hepatoma but with features of focal nodular hyperplasia.

\section{DISCUSSION}

When diaphragmatic elevation persists after a thoracoabdominal trauma, herniation of the abdominal contents should be suspected. Initial recognition of diaphragmatic rupture after trauma is important in avoiding long-term sequelae, in particular in the presence of a hepatothorax. ${ }^{3}$

Budd-Chiari syndrome is a chronic hepatic outflow obstruction of noncardiac cause. We have reported a case of a very late ( $>20$ years) presentation of a post-traumatic 


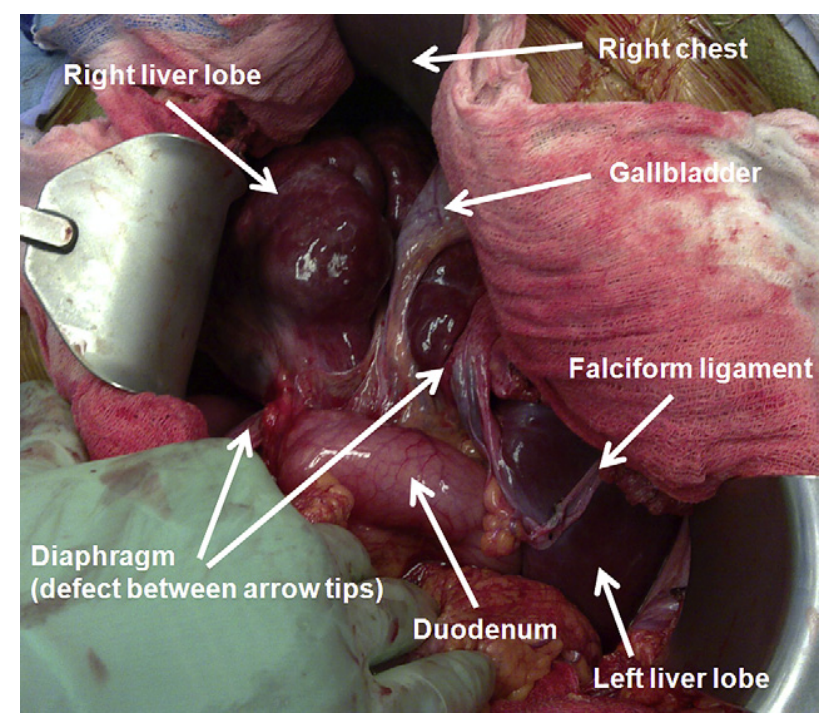

FIGURE 2. Intraoperative situs (right thoracoabdominal incision in the 8th intercostal space) showing the diaphragmatic defect with herniated and nodular right liver and healthy left liver. The herniated colon was already reduced out of the right side of the chest.

diaphragmatic hernia discovered in a 24-year-old woman. Results of imaging and pathologic examination were consistent with a Budd-Chiari syndrome limited to the right lobe of the liver. Moreover, a 1.1-cm hypervascular lesion was noted and the left lobe was hypertrophied, suggesting malfunction of the right lobe. Fortunately, the final pathologic examination did not reveal a hepatoma. A reversible Budd-Chiari-like syndrome in the liver has been described previously in 2 cases of hepatothorax after rupture of the right diaphragm. ${ }^{4}$ These patients had their diagnoses made within 15 months after the trauma, and venous outflow returned to normal after reintroduction of the liver into the abdominal cavity. In our case, the Budd-Chiari syndrome was considered to be irreversible as a result of right hepatic vein thrombosis and the very late presentation. The surgical indication was based on the radiographic finding of a hypervascular lesion (possibly a hepatoma) of $1.1 \mathrm{~cm}$ and on the need for repair of the symptomatic diaphragmatic hernia. We chose a thoracoabdominal approach, and primary suture closure of the diaphragmatic repair was sufficient, although other surgeons have previously described prosthetic mesh reinforcement. $^{5}$

Taken together, this is the first report of hepatothorax with an irreversible Budd-Chiari syndrome in a patient with post-traumatic diaphragmatic rupture, treated by right hepatectomy and primary diaphragmatic repair.

\section{References}

1. Crandall M, Popowich D, Shapiro M, West M. Posttraumatic hernias: historical overview and review of the literature. Am Surg. 2007;73:845-50.

2. Shreck GL, Toalson TW. Delayed presentation of traumatic rupture of the diaphragm. J Okla State Med Assoc. 2003;96:181-3.

3. Igai H, Yokomise H, Kumagai K, Yamashita S, Kawakita K, Kuroda Y. Delayed hepatothorax due to right-sided traumatic diaphragmatic rupture. Gen Thorac Cardiovasc Surg. 2007;55:434-6.

4. Fernandez-González AL, Llorens R, Herreros JM, Cato J, Lecumberri F, Longo J. Blunt traumatic rupture of the right hemidiaphragm and Budd-Chiari syndrome. Ann Thorac Surg. 1994;58:559-61.

5. Seket B, Henry L, Adham M, Partensky C. Right-sided posttraumatic diaphragmatic rupture and delayed hepatic hernia. Hepatogastroenterology. 2009;56: $504-7$

\title{
Removal of a large cement embolus from the right pulmonary artery 4 years after kyphoplasty: Consideration of thrombogenicity
}

\author{
Dagmar Kollmann, MD, ${ }^{\mathrm{a}}$ Konrad Hoetzenecker, MD, ${ }^{\mathrm{a}}$ Helmut Prosch, MD, ${ }^{\mathrm{b}}$ Hendrik J. Ankersmit, MD, ${ }^{\mathrm{a}}$ \\ Clemens Aigner, MD, ${ }^{\mathrm{a}}$ Shahrokh Taghavi, MD, ${ }^{\mathrm{a}}$ and Walter Klepetko, MD, ${ }^{\mathrm{a}}$ Vienna, Austria
}

\footnotetext{
From the Departments of Thoracic Surgery ${ }^{\mathrm{a}}$ and Radiology, ${ }^{\mathrm{b}}$ Medical University of Vienna, Vienna, Austria.

Disclosures: Authors have nothing to disclose with regard to commercial support.

D.K. and K.H. are equal joint first authors.

Received for publication Oct 6,2011; revisions received Dec 17, 2011; accepted for publication Jan 13, 2012

Address for reprints: Konrad Hoetzenecker, MD, Department of Thoracic Surgery, Medical University of Vienna, Währinger Gürtel 18-20, 1090 Vienna, Austria

(E-mail: konrad.hoetzenecker@meduniwien.ac.at).

J Thorac Cardiovasc Surg 2012;143:e22-4

$0022-5223 / \$ 36.00$

Copyright (C) 2012 by The American Association for Thoracic Surgery

doi: $10.1016 /$ j.jtcvs.2012.01.050
}

Percutaneous kyphoplasty is a minimally invasive procedure that has become a standard treatment for compression fractures of the spine. According to the literature, leakage of bone cement into paravertebral venous system occurs in a high percentage of cases. ${ }^{1}$ From that point, the cement can drift toward the right side of the heart and the pulmonary circulation. Current recommendations include a warfarin anticoagulant therapeutic regimen for 3 to 6 months to avoid thrombus formation on the cement embolus. Because these recommendations are solely based on case reports, however, they do not exceed evidence grade IV according to the 